\title{
Comparative study of ornamental granite cleaning using femtosecond and nanosecond pulsed lasers
}

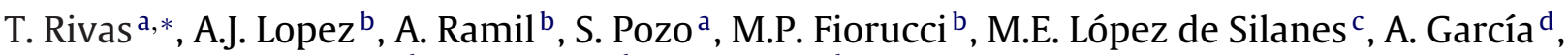 \\ J. R. Vazquez de Aldana ${ }^{d}$, C. Romero ${ }^{d}$, P. Moreno $^{d}$ \\ a Dpto. Ingeniería de los Recursos Naturales y Medioambiente. E.T.S. Ingeniería de Minas, Universidad de Vigo, 36200 Vigo Spain \\ ${ }^{\mathrm{b}}$ Centro de Investigaciones Tecnológicas. Campus de Esteiro. Universidad de A Coruña 15403 Ferrol Spain

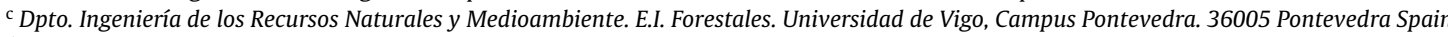 \\ ${ }^{\mathrm{d}}$ Grupo de Investigación en Microprocesado de Materiales con Laser. Facultad de Ciencias, Universidad de Salamanca, 37008 Salamanca Spain
}

\section{A R T I C L E I N F O}

\section{Article history:}

Received 15 June 2012

Received in revised form

26 November 2012

Accepted 6 December 2012

Available online 17 December 2012

\section{Keywords:}

Granite

Femtosecond laser

Nanosecond laser

Biological crust

Laser cleaning

\begin{abstract}
A B S T R A C T
Granite has been widely used as a structural and ornamental element in public works and buildings. In damp climates it is almost permanently humid and its exterior surfaces are consequently biologically colonized and blackened We describe a comparative analysis of the performance of two different laser sources in removing biological crusts from granite surfaces: nanosecond $\mathrm{Nd}: \mathrm{YVO}_{4}$ laser $(355 \mathrm{~nm})$ and femtosecond Ti:Sapphire laser at its fundamental wavelength $(790 \mathrm{~nm})$ and second harmonic $(395 \mathrm{~nm})$. The granite surface was analyzed using scanning electron microscopy, attenuated total reflection Fourier transform infrared spectroscopy and profilometry, in order to assess the degree of cleaning and to characterize possible morphological and chemical changes caused by the laser sources.
\end{abstract}

(c) 2012 Elsevier B.V. All rights reserved.

\section{Introduction}

The use of laser to clean surface deposits from the ornamental stone used for heritage buildings has been widely studied, mainly for sedimentary (limestone and sandstone) and metamorphic (marble) rock [1-5 and references therein] and particularly referring to optimized cleaning using excimer or nanosecond solidstate pulsed lasers. Contrasting with the abundant literature on the application of laser to the stones listed above are the relatively few studies regarding applications to granite, primarily because this rock is especially complex due to its polymineral nature. Although the effects of irradiating ornamental granite with an Nd:YAG laser at $1064 \mathrm{~nm}$ have been analyzed by several authors [6,7], the laser was applied directly to rock with no patina or crust. Another study analyzed the efficiency of cleaning beeswax present in granite using a Nd:YAG laser operating at different wavelengths $(266,355,532$ and $1064 \mathrm{~nm}$ ) [8]; however, it included no analysis regarding the effect of the radiation on the properties of the rock substrate. Other studies have described $\mathrm{Nd}: \mathrm{YVO}_{4}$ laser application to granite using the third harmonic ( $355 \mathrm{~nm})$ to remove graffiti [9] and biological

\footnotetext{
* Corresponding author. Tel.: +34 986811922.

E-mail address: trivas@uvigo.es (T. Rivas).
}

crusts $[10,11]$, with satisfactory results. These studies [6,7,9-11] describe the harmful effects of nanosecond pulsed lasers on the granite, reporting that certain minerals tend to be altered, most particularly biotite and feldspar, which show melting behaviour.

In recent years, ultrashort laser pulses (<picosecond) have emerged as a new precision tool for removing material from any surface. In the heritage conservation area, the effectiveness of this approach for cleaning paints and varnishes [12,13], parchments [14] and metals [15] has been evaluated. The outstanding properties of the strong non-linear interaction with matter in these laser pulses make them an interesting alternative to nanosecond pulsed lasers $[16,17]$. The extremely small thermal load of the substrate resulting from irradiation with ultrashort laser pulses minimizes any collateral effect induced by heat conduction, such as charring, cracking, chemical modifications, etc. At the same time, the nonlinear nature of the interaction offers the possibility of removing layers of material at a nanometric scale with very high precision and control.

In this research, highly biologically colonized ornamental granite samples were cleaned using Ti:Sapphire femtosecond laser pulses using two wavelengths, the fundamental wavelength $(790 \mathrm{~nm})$ and the second harmonic $(395 \mathrm{~nm})$, in order to determine the role of wavelength in cleaning efficiency and in possible damage to the rock-forming minerals. To our knowledge, this is the 
first study on the use of ultrashort laser pulses for the cleaning of granitic rocks.

The results obtained with femtosecond laser pulses in nearinfrared and UV wavelengths were also compared with the results obtained with nanosecond laser pulses from a $\mathrm{Nd}: \mathrm{YVO}_{4}$ source (third harmonic, $355 \mathrm{~nm}$ ) in order to evaluate the influence of pulse duration and wavelength on the stability of the granite minerals.

\section{Material and methods}

\subsection{Granite and biological crust}

Experiments were carried out on slabs of an ornamental granite (called Vilachán) of great commercial value from Galicia (NW Spain) and traditionally used in the construction of historical buildings in this region. This granite is classified as a fine-grained adamellite with a heterogranular panalotriomorphic texture [18]. Vilachán granite is composed of quartz (47\%), potassium feldspar (10\%), sodium plagioclase (15\%), biotite (7\%) and muscovite $(18 \%)$ as the main minerals. Grain size for the different minerals oscillates between $2 \mathrm{~mm}$ and $0.3 \mathrm{~mm}$. The open porosity of the rock [determined following 19] is $2.82 \%$.

For this research we used rock specimens with disc-saw finished surfaces; these were exposed to the natural environment for almost three years, resulting in intense blackening of the rock surfaces. Visualization by optic microscopy revealed that the crust was formed of hyphae of a lichen prothallum and numerous black spheres corresponding to cyanobacteria interspersed with unicellular Chlorophyceae algae, covered with a growth of small whitish flakes of a lichen thallus belonging to the Trapelia genus (a pioneer granite taxon in the Atlantic climate $[20,21])$. Scanning electron microscope (SEM) images (Fig. 1) showed biological structures with a spherical morphology corresponding to algae cells. Filamentous structures could also be appreciated that may correspond to fungal hyphae. Crust coverage of the surface of the rock was extensive. Viewing of transversal sections of the colonized granite under a petrographic microscope revealed an average thickness of $40 \mu \mathrm{m}$.

\subsection{Laser cleaning}

Femtosecond (fs) laser irradiation was carried out with the linearly polarized output of a system consisting of a Ti:Sapphire oscillator (Tsunami, Spectra Physics) and a regenerative amplifier system (Spitfire, Spectra Physics) based on the chirped pulse amplification technique. The system produces $120 \mathrm{fs}$ pulses at $790 \mathrm{~nm}$ with a repetition rate of $1 \mathrm{kHz}$ and a maximum pulse energy of $1 \mathrm{~mJ}$. Pulse energy was finely controlled by a half-wave plate and a linear polarizer. Neutral density filters were used for further energy reduction. The average power of the beam was measured using a thermopile detector (407 A, Spectra Physics). The transversal mode was a near-Gaussian TEM00 with a $10 \mathrm{~mm}$ beam diameter (at $1 / e^{2}$ ). The second harmonic of the fundamental laser output $(395 \mathrm{~nm})$ was generated in a $0.5 \mathrm{~mm}$ thick BBO crystal (type-I, $\Theta=29^{\circ}$ ) with a maximum energy per pulse of $0.14 \mathrm{~mJ}$. Pulse duration (measured by cross correlation with the fundamental pulses) was approximately $130 \mathrm{fs}$.

The nanosecond (ns) laser used was an Nd:YVO 4 laser (Coherent AVIA Ultra 355-2000). This system produces $25 \mathrm{~ns}$ pulses at $355 \mathrm{~nm}$ and a maximum pulse energy of $0.1 \mathrm{~mJ}$, with a repetition rate which can be selected from single shot to $100 \mathrm{kHz}$. The intensity profile at the laser output was near Gaussian $(\mathrm{M} 2<1.3)$ and the beam diameter at $1 / e^{2}$ intensity level was about $2.2 \mathrm{~mm}$.

Irradiation of the samples, in both fs and ns laser sources, was performed in ambient air. The beam impinged perpendicularly onto the target surface, placed on a motorized XYZ translation stage where the $Z$ axis was perpendicular to the sample surface.

In the case of the fs laser, the pulses were focused on the surface by a combination of two cylindrical lenses with their astigmatic axes crossed. A lens of $f=20 \mathrm{~mm}$ was used to focus the beam onto the sample in one axis. A second $f=75 \mathrm{~mm}$ lens, placed $30 \mathrm{~mm}$ in front of the $f=20 \mathrm{~mm}$ lens, reduced beam size by a factor of three along the opposite axis. Under these conditions, the spot size at the sample was $1 \times 2000 \mu \mathrm{m}^{2}$. Homogeneous irradiation within a $5 \times 5 \mathrm{~mm}^{2}$ area was achieved by using a square mask placed on the surface of the sample and scanning along the direction of the smallest spot dimension. With respect to the ns laser, a Galilean beam expander was arranged consisting of two plano-spherical lenses: a divergent lens with $f=-12.5 \mathrm{~mm}$ and a convergent lens with $f=+100 \mathrm{~mm}$. The emergent parallel beam $(\approx 20 \mathrm{~mm}$ diameter) was focused by a convex lens of $f=+150 \mathrm{~mm}$, resulting, in the paraxial approximation, in a diameter of $D \approx 100 \mu \mathrm{m}$ at the beam waist and in an energy density of around $2.5 \mathrm{~J} / \mathrm{cm}^{2}$. Homogeneous irradiation of the target within $10 \mathrm{~mm} \times 10 \mathrm{~mm}$ was achieved by scanning the beam along parallel lines in the $X$ direction followed by perpendicularly crossing lines along the $Y$ direction.

Owing to the number of parameters involved in laser treatments, decisions about the most adequate values for biological crust removal, for both the fs and ns laser sources, were made
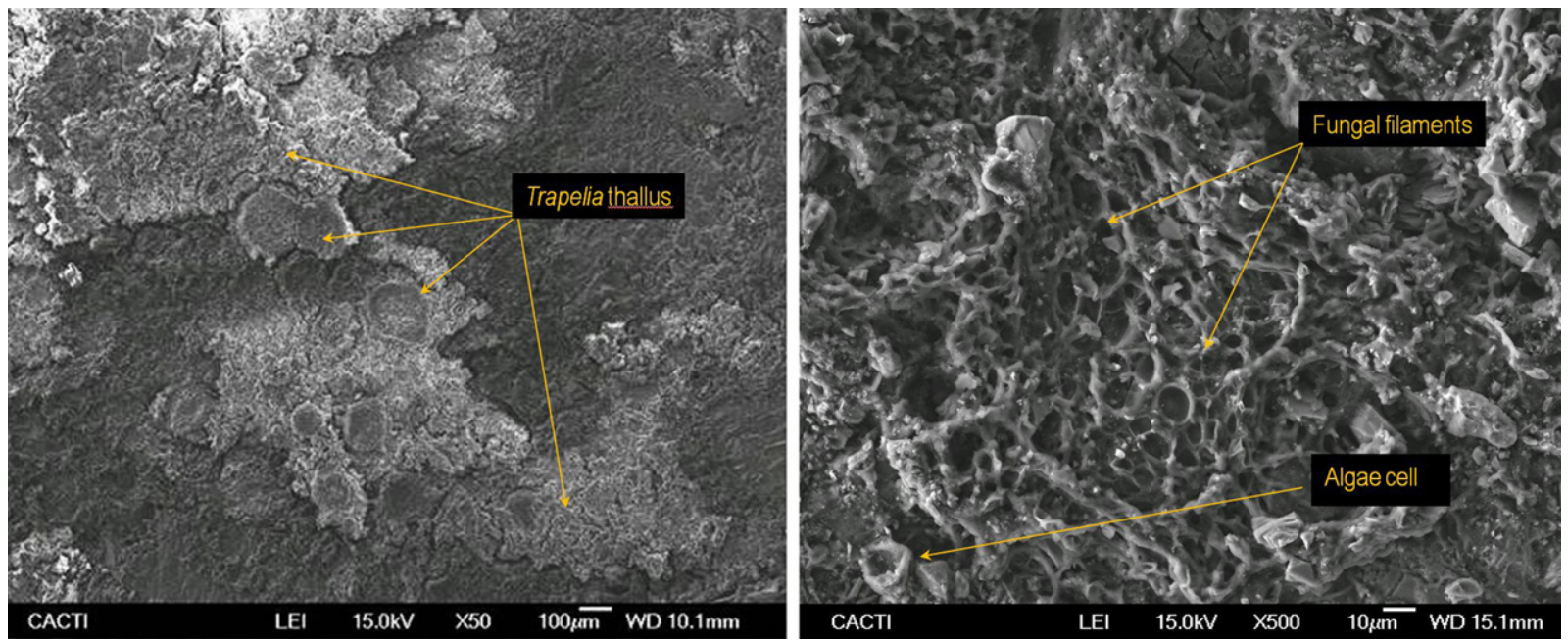

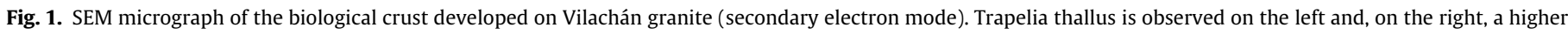
magnification reveals algae cells and fungal filaments. 
Table 1

Irradiation parameters for $25 \mathrm{~ns} \mathrm{Nd}: \mathrm{YVO}_{4}$ and fs Ti:Sapphire laser sources ( $120 \mathrm{fs}$ for $\lambda=790 \mathrm{~nm}$ and $130 \mathrm{fs}$ for $\lambda=395 \mathrm{~nm}$ ). Wavelength $\lambda$, maximum pulse energy $E_{\text {pulse }}$, repetition rate $f_{\text {rep }}$, scan speed $v$ and separation between adjacent laser passes $L_{\text {sep }}$ are shown.

\begin{tabular}{lllccc}
\hline Laser source & $\Lambda(\mathrm{nm})$ & $E_{\text {pulse }}(\mu \mathrm{J})$ & $f_{\text {rep }}(\mathrm{kHz})$ & $v(\mu \mathrm{m} / \mathrm{s})$ & $L_{\text {sep }}(\mu \mathrm{m})$ \\
\hline ns Nd:YVO & 355 & 100 & 10 & 20000 & 75 \\
fs Ti:Sapphire & 395 & 130 & 1 & 240 & 500 \\
fs Ti:Sapphire & 790 & 300 & 1 & 120 & 500 \\
\hline
\end{tabular}

through a series of exploratory experiments, bearing in mind previous studies of granites [9-11]. The results of these preliminary tests were evaluated by visual inspection assisted by optical microscopy. The irradiation conditions finally selected for this study were those that led (under optic microscopy) to a neat granite surface without appreciable biological crust remains and without visible damage to rock-forming minerals.

Table 1 summarizes these parameters for ns and fs laser irradiation; i.e., pulse wavelength $\lambda$, maximum pulse energy $E_{\text {pulse }}$, pulse repetition rate $f_{\text {rep }}$ and finally, scan speed $v$ and separation between adjacent laser passes $L_{\text {sep }}$.

Given the differences between the experimental arrangements and irradiation procedures, energy distribution over the target surface was determined in both laser systems in order to compare the two laser domains. For this purpose, it was necessary to determine the pulse overlap in both the $X$ direction (the scanning direction) and the $Y$ direction (lateral overlap between adjacent laser trajectories) and also the accumulated energy deposited by a Gaussian beam that runs along the surface according to the scheme above.

Table 2 presents values for fluence $F$ (maximum pulse energy $E_{\text {pulse }}$ divided by spot diameter $D$ ), the number of pulses per point $R$, where $R$ is $R=\left(D \times f_{\text {rep }}\right) / v$ both in the scanning direction $R_{x}$ and transverse direction $R_{y}$, with the overlap computed as the percentage of the Gaussian height where two adjacent pulses matched, i.e., $S=\exp \left[-2 / R^{2}\right]$. Finally, the accumulated energy density Fa corresponds to the average value, for a standard deviation below $10 \%$ that ensures homogeneous laser treatment over the entire target surface.

\subsection{Evaluation of efficiency}

For the evaluation of cleaning efficiency, an initial assessment was made under an optical microscope (Nikon Eclipse L150). SEM with energy dispersive X-ray spectrometry (SEM-EDX) (JEOL ${ }^{\circledR}$ JSM 6400) was also used to characterize efficiency in removing the biological crust and the effects of the lasers on rock-forming minerals in the granite. Fourier transform infrared (FTIR) spectroscopy, based on a Thermo ${ }^{\circledR}$ Nicolet 6700 in attenuated total reflection (ATR) mode, was also used to assess the existence of biological remains on the granite surfaces.

Cleaned surfaces were also characterized by a non-contact optical profiling system using a profilometer (Wyko-NT 1100). Data on mean roughness were obtained by vertical scanning interferometry (VSI) mode (for a measurement range of $2 \mathrm{~mm}$ and a vertical resolution for multiple measures of less than $1 \mathrm{~nm}$ ). The data were collected using a $5 \times$ magnification and with an intermediate field of vision (FOV) lens of $1 \times$. In the case of fs cleaning, we worked with areas of $4 \mathrm{~mm} \times 4 \mathrm{~mm}$ (involving 24 images). In the case of $\mathrm{ns}$ cleaning, we chose an area of $7 \times 7 \mathrm{~mm}^{2}$ (involving 80 images). Data were obtained for the cleaned samples before ns and fs laser cleaning, taking the uncolonized and non-irradiated granite surface for comparative reference purposes.

\section{Results and discussion}

\subsection{Effective crust removal}

Optic microscopy of samples cleaned with fs laser revealed this laser's very good capacity for removing biological crusts: lichen thallus remains were rare and observed only in deeper cracks inaccessible to laser (Fig. 2). The efficiency of biological crust removal was similar for both the $790 \mathrm{~nm}$ and $395 \mathrm{~nm}$ wavelengths. SEM revealed that there were hardly any remains of a biological nature on these surfaces (Fig. 2). Observed, however, were small stains scattered over the surface which the back-scattered electron (BSE) detector revealed to have very low contrast. The energy dispersive probe detected only carbon in these stains. Biological structures were not identified in these remains, so maybe they were ablated organic material deposited on the surface after applying the laser [22].

The efficiency of crust removal by fs laser was similar to that for ns laser. In samples cleaned with the latter, thallus remains were only observed in the deepest recesses of the rock and SEM also detected low-contrast stains rich in carbon.

The results obtained via FTIR confirmed the microscopy results. Fig. 3 shows the FTIR spectrum corresponding to the granite with a biological crust, uncolonized granite (saw-disc finished surface) and the surfaces cleaned with the fs laser under both wavelengths and with the ns laser.

The crust had bands assigned to functional groups common in biological compounds (carbohydrates, amino acids, etc. [23]). The most characteristic bands were those around $1200-1700 \mathrm{~cm}^{-1}$ and around $2500-3400 \mathrm{~cm}^{-1}$. The band at $1267 \mathrm{~cm}^{-1}$ is assigned to the functional group $\mathrm{C}-\mathrm{O}-\mathrm{C}(\mathrm{C}-\mathrm{O}-\mathrm{C}$ asymmetric stretching vibration), although this band, together with the band at $1650 \mathrm{~cm}^{-1}$, was assigned to the amide group of amino acids in another study [24]. The band at $1316 \mathrm{~cm}^{-1}$ (which can also correspond to stretching vibrations for the $\mathrm{C}-\mathrm{O}-\mathrm{C}$ group) is assigned in the same study [24] to asymmetric stretching vibration for the sulphone group $\left(\mathrm{SO}_{2}\right)$. The peak at $1375 \mathrm{~cm}^{-1}$ is assigned to asymmetric $\mathrm{NO}_{2}$ stretching vibration. The band at $1470-1490 \mathrm{~cm}^{-1}$ is typically assigned to aliphatic esters $\left(-\mathrm{OCH}_{3}\right.$; asymmetric $-\mathrm{CH}_{3}$ stretching vibration). Detected at $1500-1650 \mathrm{~cm}^{-1}$ was the functional group $\mathrm{C}=\mathrm{C}$ (alkene $\mathrm{C}=\mathrm{C}$ stretching vibration), assigned to the chlorophyll chromophores [25]. The peaks at around $1600 \mathrm{~cm}^{-1}$ are assigned to the ester, aldehyde and ketone groups and the two peaks at $2890 \mathrm{~cm}^{-1}$ and $2920 \mathrm{~cm}^{-1}$ correspond to $\mathrm{CH}$ stretching (asymmetric vibrations of alkanes), in this case indicative of the presence of organic matter. The shoulder at around $3300 \mathrm{~cm}^{-1}$ is assigned to hydrogenbonded (intermolecular) $\mathrm{OH}$ and is indicative of water associated with organic tissues.

Detected in the spectrum of the rock without crust are characteristic bands of silicates, which appear mainly at $590-730 \mathrm{~cm}^{-1}$, $1180-860 \mathrm{~cm}^{-1}$ and $1100-900 \mathrm{~cm}^{-1}$ [23]. Regarding the $\mathrm{Si}-\mathrm{O}$ functional group, the variations in position and intensity of these bands in the spectra are all as expected, bearing in mind that each spectrum is taken at different positions of the sample, thereby collecting the signal for different silicates in the sample.

The spectra for the samples cleaned with fs laser in the two wavelengths (Fig. 3) were similar. Detected in both were the characteristic bands of silicates ( $\mathrm{Si}-\mathrm{O}$, at around $460-1190 \mathrm{~cm}^{-1}$ ). Of the characteristic bands of the crust, only a slight peak was detected at $1652 \mathrm{~cm}^{-1}$, assigned to the functional group $\mathrm{C}=\mathrm{C}$ (alkene $\mathrm{C}=\mathrm{C}$ stretching vibration), and a very slight shoulder at around $3400 \mathrm{~cm}^{-1}$ (hydrogen-bonded $\mathrm{OH}$ ). The reduction in the intensity of these two bands and the disappearance of the remaining peaks described for the crust indicate that the biological crust was almost completely removed via fs laser in both wavelengths. In both spectra there was an effect close to $3700 \mathrm{~cm}^{-1}$, 

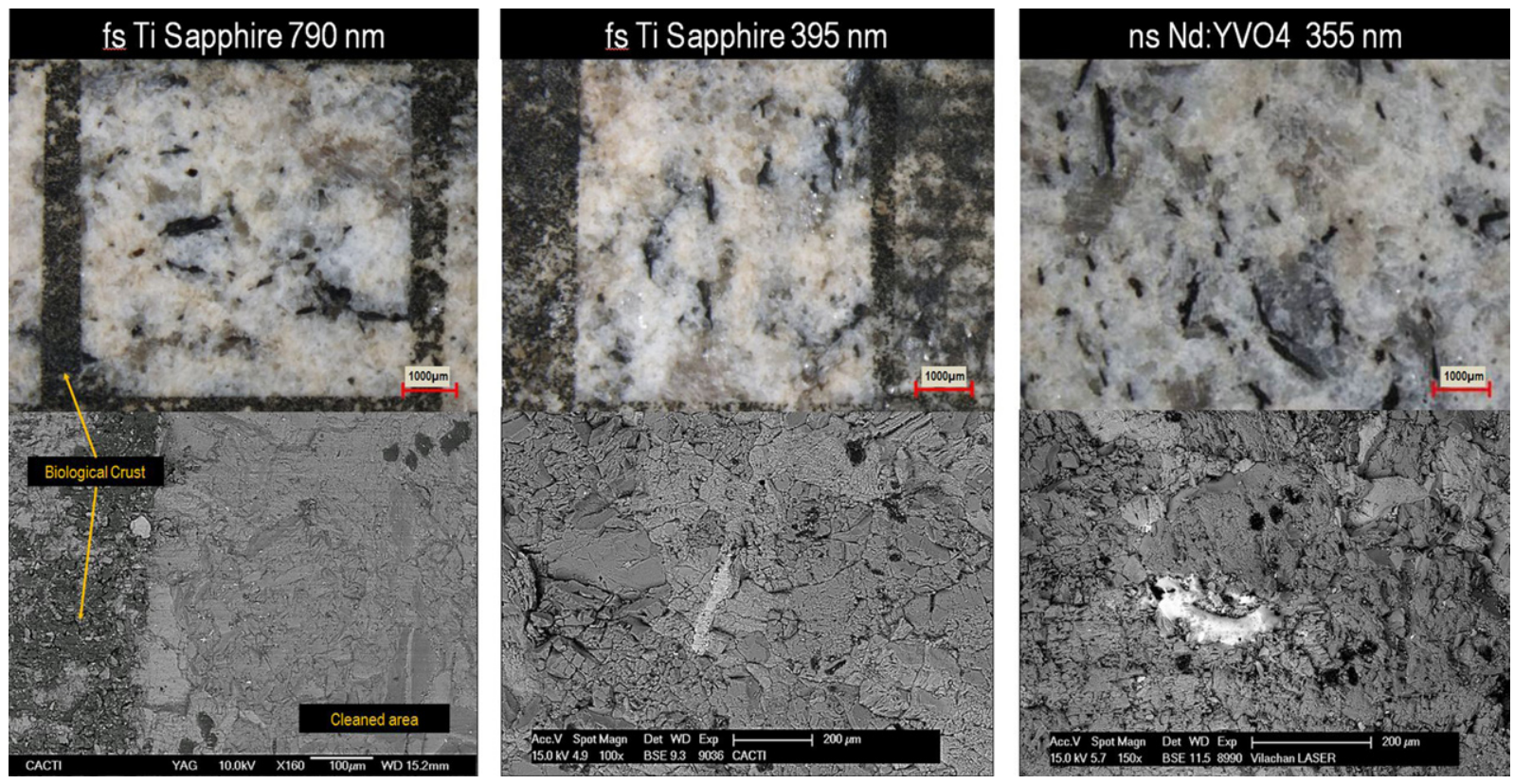

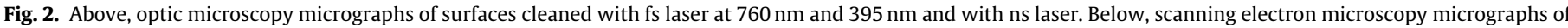
the same surfaces (back-scattered electron mode).

usually assigned to $\mathrm{OH}$ groups in coordination with metals [21] in these rocks, this effect may correspond to the forms of iron of different degrees of crystallinity and hydration that cover the cracks and responsible for the characteristic brown colour. Due to its irregular and dispersed distribution throughout the rock mass, it is not expected to be found in all the spectra.

Detected in samples cleaned with fs laser was a shoulder at $2630 \mathrm{~cm}^{-1}$ which could not be assigned with any certainty to any functional group. The fact that this is also observed in the spectrum of the rock without crust (although much less intensely) would indicate that the effect is not attributable to the presence of colonizing organisms but to the mineral environment of the rock. It would be necessary to consider whether mineral components in the rock are altered chemically by the laser and that, as a result, intensity in the samples cleaned with fs laser is higher than in the original uncleaned rock samples.

With respect to the spectrum of rock cleaned with ns laser (Fig. 3), of note is the persistence of the peaks corresponding to $\mathrm{CH}$ stretching asymmetric $\mathrm{CH}$ vibrations of alkanes $\left(2850-2915 \mathrm{~cm}^{-1}\right)$ and the mild bands at 1400 and $1700 \mathrm{~cm}^{-1}$, assignable to the ester and the alkene groups. Given that the cleanliness for ns laser was very satisfactory and similar to that for fs laser, the fact that these bands may be due to external contamination needs to be considered.

\subsection{Mineral damage}

SEM observation of samples revealed that ultrashort pulsed laser radiation causes morphological changes in the surface of the minerals (Figs. 4 and 5). These changes differed depending on the wavelength; they also differed from those caused by the ns laser. The minerals affected by the fs laser were biotite and, to a lesser extent, potassium feldspar, both of which showed signs of melting. The ns laser also affected muscovite, which also melted.

Figs. 4 and 5 show different micrographs of granite cleaned with the fs laser at $790 \mathrm{~nm}$ and $395 \mathrm{~nm}$ and with the ns laser. To facilitate comparison, micrographs of uncolonized and non-irradiated granite are also provided. With respect to the biotite (Fig. 4), radiation at $790 \mathrm{~nm}$ caused the mineral to melt, generating on the surface a granulate at the micrometre scale. All the mineral grains observed had this aspect (micrographs B, F and J). At $395 \mathrm{~nm}$, the effects on the biotite appeared to be less intense. Fig. 4 shows an image at $190 \times$ (micrograph C), indicating that the effect on the biotite varied between crystals, with some crystals showing no evidence of melting. When sufficiently magnified, the surfaces of the most affected grains showed a slight roughness not observed in the grains of non-irradiated biotite, suggesting that they were affected by radiation, even if less intensely. The ns laser produced a more intense melting of the mineral, as can be seen from the fusion crusts and the amorphous-like texture acquired by the mineral (micrographs D and H). Muscovite was not affected by the fs laser but melted under the ns laser, with an intensity and morphology similar to biotite. In both minerals, the cleavage planes disappeared.

As for potassium feldspar, this was affected by the fs laser only under radiation at $790 \mathrm{~nm}$. Fig. 5 shows that, with this wavelength, the mineral surface became very rough (micrographs $\mathrm{F}$ and $\mathrm{I}$ ) but the grains maintained the characteristic cleavage planes intact

Table 2

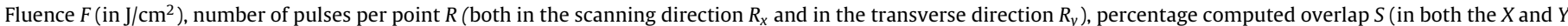
directions) and the accumulated energy density $F_{\text {acc }}$ in $\mathrm{J} / \mathrm{cm}^{2}$.

\begin{tabular}{|c|c|c|c|c|c|c|c|}
\hline Laser & $\lambda(\mathrm{nm})$ & $F$ & $R_{x}$ & $S_{x}$ & $R_{y}$ & $S_{y}$ & $F_{\mathrm{acc}}$ \\
\hline ns Nd:YVO & 355 & 0.1019 & 125 & 99.997 & 3.333 & 95.6 & 131.947 \\
\hline fs Ti: Sapphire & 395 & 16.552 & 4.167 & 89.119 & 4 & 88.23 & 97.492 \\
\hline fs Ti: Sapphire & 790 & 38.197 & 8.333 & 97.161 & 4 & 88.23 & 449.986 \\
\hline
\end{tabular}




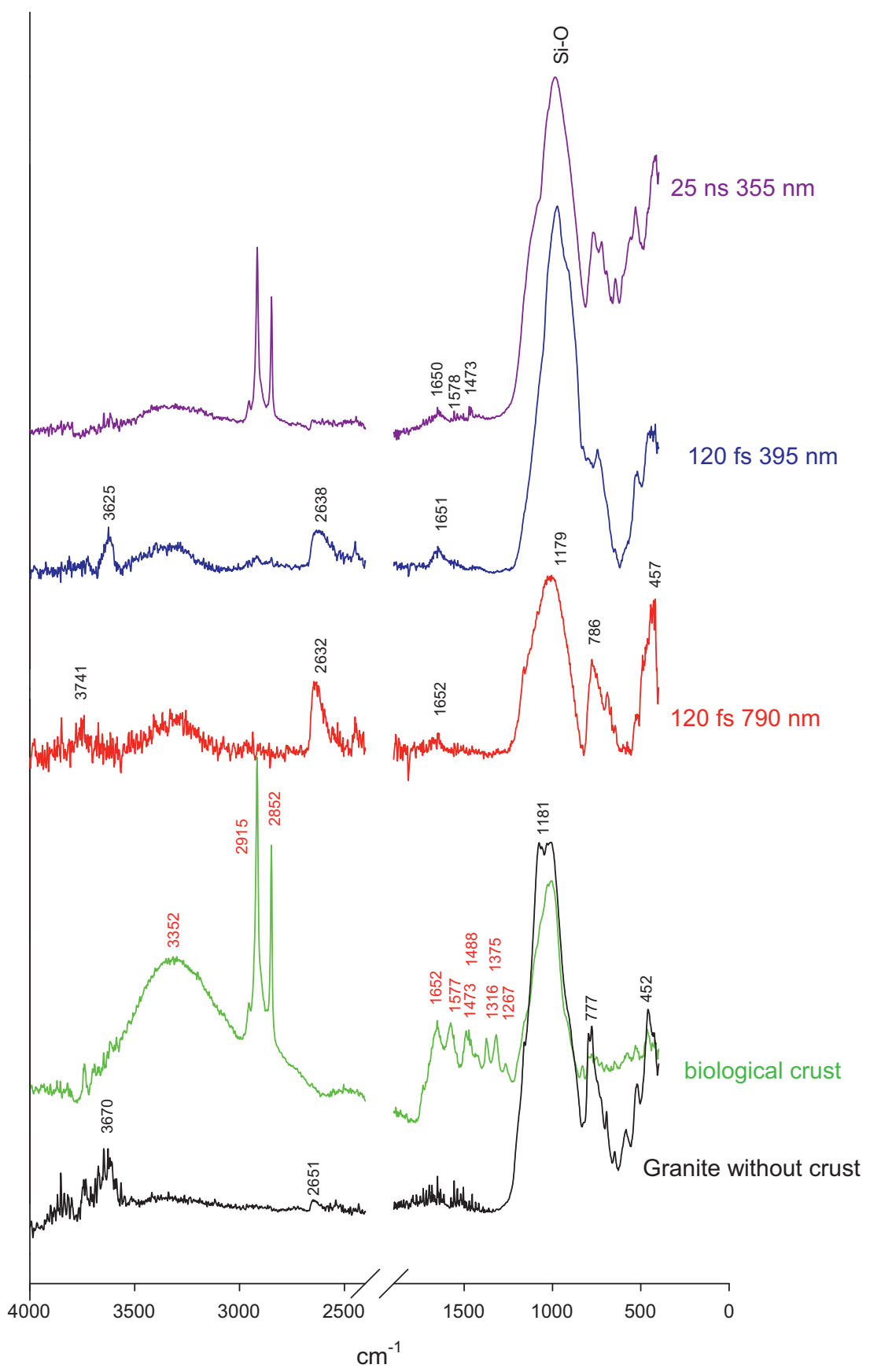

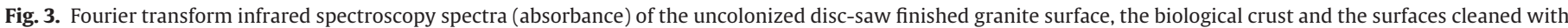
fs Ti:Sapphire laser at $790 \mathrm{~nm}$ and $395 \mathrm{~nm}$ and with $\mathrm{ns} \mathrm{NdY}: \mathrm{VO}_{4}$ laser.

(micrograph F). At $395 \mathrm{~nm}$, however, the mineral was unaltered. The ns laser, on the other hand, strongly modified the surface of the mineral and, at some points, melting was strong enough to generate a fusion crust (micrographs $\mathrm{H}$ and $\mathrm{K}$ ). The grid generated by the passage of the laser, however, removed the typical texture of this mineral defined by its cleavage planes, softening the relief of the sample (micrograph D in Figs. 4 and 5).

The morphology of the mineral alterations observed under SEM suggests that the thermal effects on the silicates were less when short-pulse laser was used, which would confirm, for these minerals, the advantage of fs laser over ns laser. In the fs domain, the ultraviolet (UV) wavelength $(395 \mathrm{~nm})$ caused changes that were apparently less intense than in the $790 \mathrm{~nm}$ wavelength, affecting only the less stable silicate, namely, biotite (whose melting temperature is $571^{\circ} \mathrm{C}$, compared to $1713^{\circ} \mathrm{C}$ and $1200^{\circ} \mathrm{C}$, respectively, for quartz and feldspar).

Table 3 shows the optical profilometry results for the surfaces cleaned with fs laser for two wavelengths, the surface cleaned

Table 3

Roughness data (in $\mu \mathrm{m}$ ) for samples cleaned with ns and fs lasers and for uncolonized and non-irradiated granite. Ra: average roughness; Rq: root mean square roughness; Rz: average maximum height; Rt: maximum peak-to-valley height.

\begin{tabular}{lrlll}
\hline & $\mathrm{Ra}(\mu \mathrm{m})$ & $\mathrm{Rq}(\mu \mathrm{m})$ & $\mathrm{Rz}(\mu \mathrm{m})$ & $\mathrm{Rt}(\mu \mathrm{m})$ \\
Granite without crust & 10.6 & 15.6 & 338.0 & 379.3 \\
ns NdY:VO & 8.5 & 12.1 & 156.9 & 157.4 \\
fs Ti:Sapphire 790 nm & 12.2 & 16.1 & 196.6 & 208.4 \\
fs Ti:Sapphire 395 nm & 16.1 & 22.5 & 232.4 & 247.1 \\
\hline
\end{tabular}



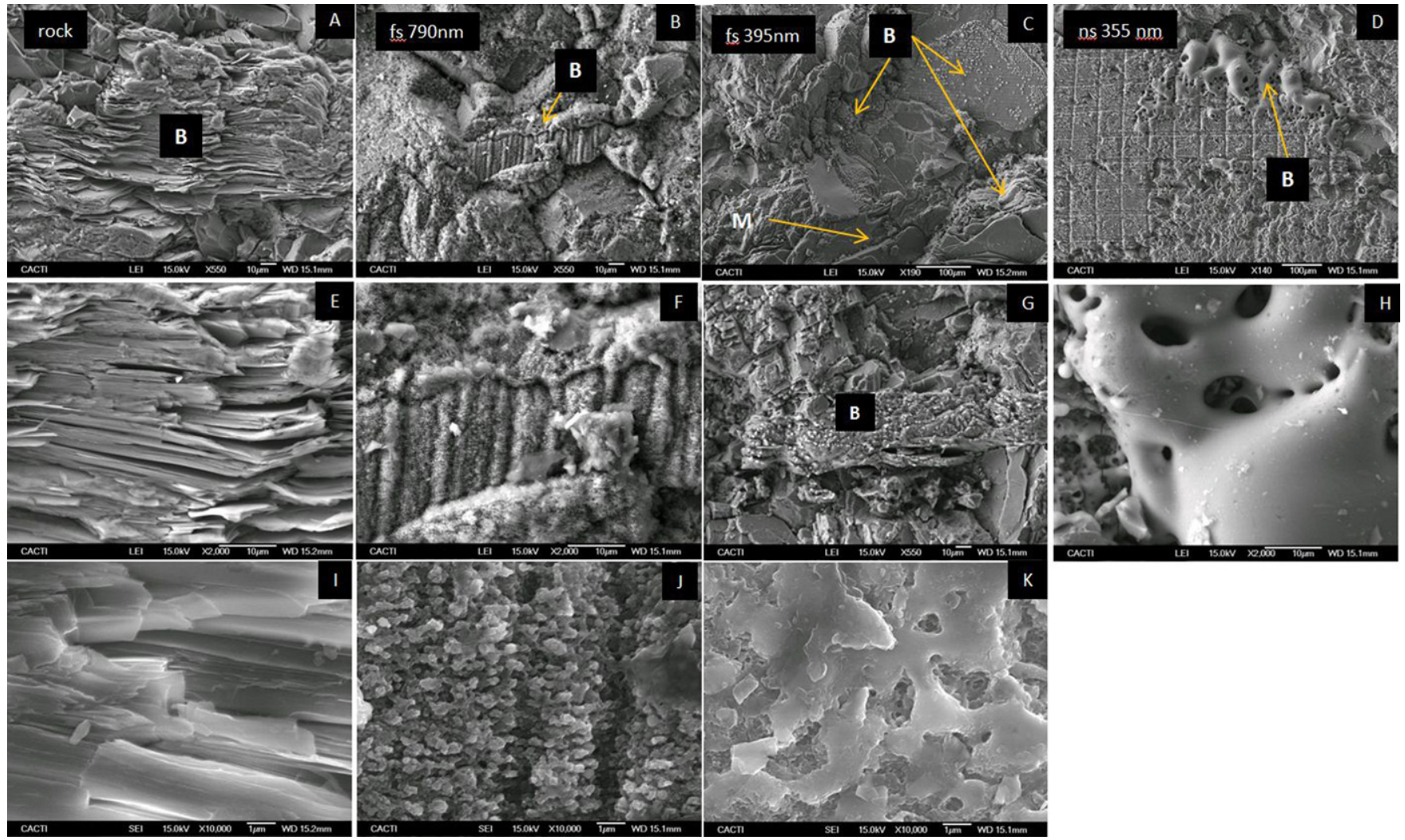

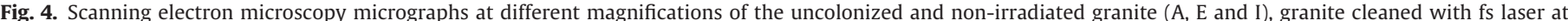

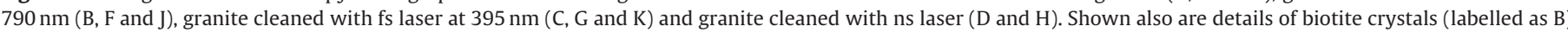
and the textural modifications at a higher magnification.
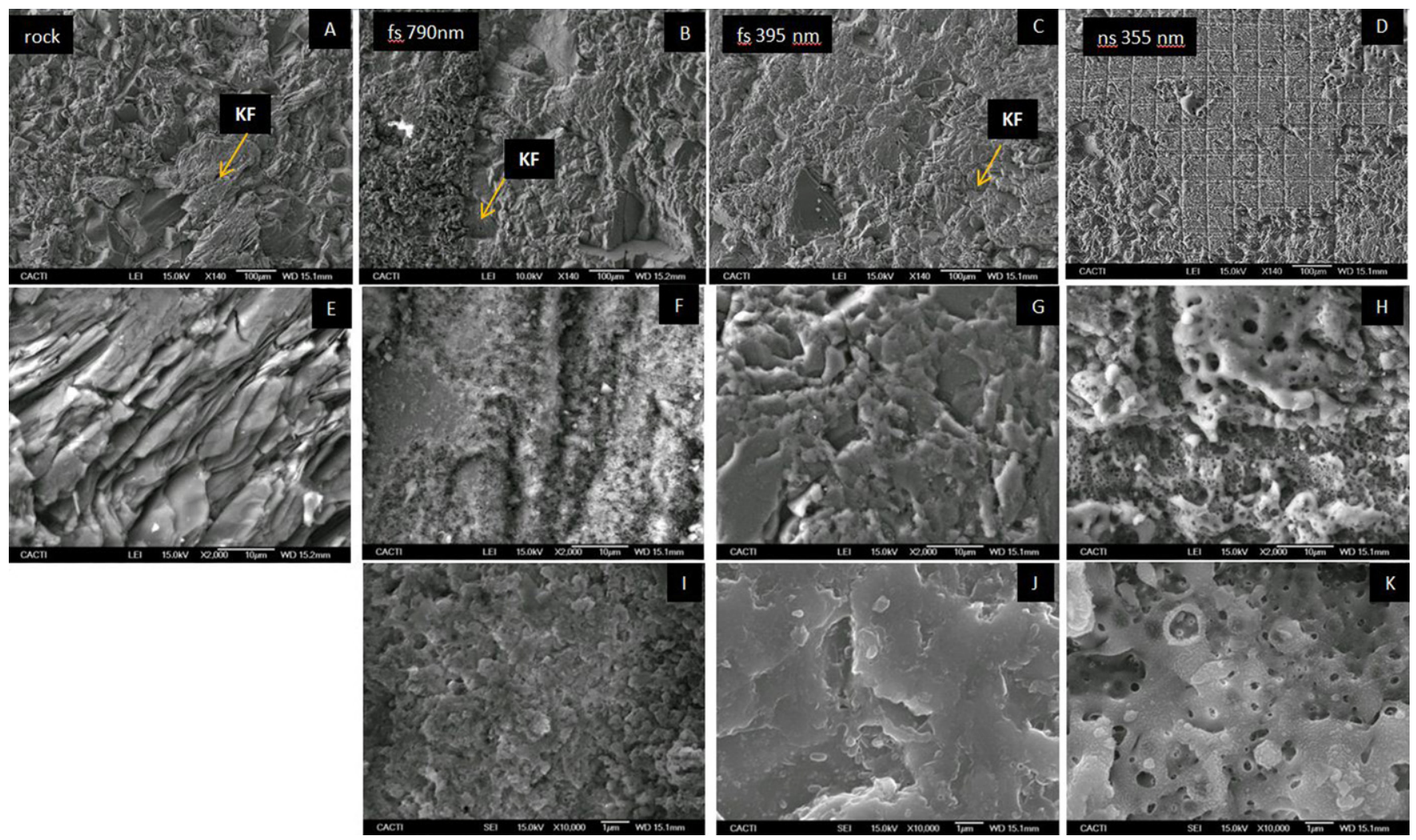

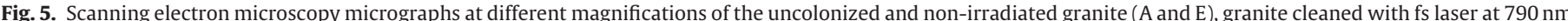

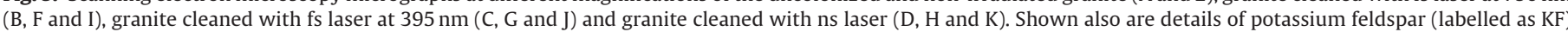
crystals and the textural modifications at a higher magnification. 
with ns laser and for the uncolonized and non-irradiated granite. Although the profilometry measurement areas were different for the ns and fs lasers, both were sufficiently large to enable characterization of the roughness of surfaces as heterogeneous as those as granite, thereby yielding sufficiently robust values from the statistical point of view.

It can be observed that the fs laser increased, and the ns laser reduced, the mean roughness value of the rock. The average maximum height $(\mathrm{Rz})$ and the maximum peak-to-valley height (Rt) decreased after cleaning with both lasers, although slightly more so in the case of the ns laser.

The reduction in roughness after ns laser application can be explained by the morphology of the changes in the mineral constituents of the rock. Biotite and muscovite, whose laminar habit contributes to high Rz and Rt values (especially if they have their 001 planes perpendicular to the surface), were converted into grains with completely smooth surfaces (Fig. 4), thereby losing the relief associated with their cleavage planes. This caused a reduction in $\mathrm{Rz}$ and $\mathrm{Rt}$ and in the mean roughness value. Something similar occurred with feldspar. The transformation of its surfaces into fusion crust also reduced mean roughness and the $\mathrm{Rz}$ and $\mathrm{Rz}$ values by eliminating the relief associated with the mineral habit and therefore reducing the difference between peaks and valleys (Fig. 5). On the surfaces of the biotite and feldspar affected by fs laser, the micrometric granulate generated caused average roughness to increase, but, unlike what happened with ns laser, the cleavage planes did not disappear. This explains why the Rz and Rt parameters were more similar to those for uncolonized and nonirradiated rock. Striking, however, was the high mean roughness value for the sample cleaned with fs laser at $395 \mathrm{~nm}$ : the feldspar remained intact and only the biotite was modified.

\section{Conclusions}

Our main conclusion is that fs laser pulses, both in the nearinfrared and UV wavelengths, perform well in removing biological crusts from granite surfaces. Even though a limited number of processing parameters were used, the results would indicate that crust removal efficiency was high and comparable to other techniques, including ns lasers. The absence of characteristic peaks in the biological crust in the FTIR spectra confirms the efficiency of the fs laser in cleaning granite surfaces.

From the morphological point of view, fs laser as compared to ns laser seems to better respect the original morphology of the granite surface. The thermal nature of cleaning for the ns laser induces a flattening of the granite surface as a result of the melting of rock-forming materials. For fs pulses, a typical microstructure of ultrafast ablation emerges, resulting from phase explosion events at the nano- and micrometre scale. Nonetheless, the morphology of the mineral grains is not affected, but rather respects the relief associated with mineral cleavage planes. In the case of UV pulses, this feature affects biotite but not feldspar. This is a real advantage for fs laser cleaning as compared to ns laser cleaning.

Optical profilometry results indicate an increase in mean roughness with regard to non-irradiated granite which may be associated with the aforementioned microstructural changes; Rz and Rt values, meanwhile, are reduced but to a lesser extent than for ns cleaned surfaces.

The seemingly minimal damage caused by fs laser and its proven effectiveness in eliminating biological crusts would indicate the value of further research aimed at optimizing the use of short pulsed lasers and UV radiation to remove biological crusts in granite. Nonetheless, short pulses cause a significant increase in mean roughness and it is not known what effect the alteration of the mineral surface could have on mineral stability against weathering processes. This uncertainty is compounded by the fact that the changes observed in this study were only descriptive. It is therefore necessary to investigate whether chemical changes occur in the altered surfaces of minerals and also whether changes in the chemical composition of the affected area could determine a different kind of susceptibility to deterioration. Knowledge of the nature of these changes and how they might be different for the fs and ns laser techniques is a fundamental issue as it would help identify which domain (fs or ns) and which conditions of application could be ideal for cleaning granite.

\section{Acknowledgments}

This work is supported by the CTM2010-19584, FIS2009-09522 and CSD2007-00013 research projects (Ministerio de Ciencia y Tecnología, Spanish Government) and by SA086A12-2 project (Junta de Castilla y León, Spain). FTIR, profilometry and SEM analyses were conducted at the University of Vigo's research centre (CACTI). Ailish Maher assisted with the English in a version of this manuscript.

\section{References}

[1] V. Vergès-Belmin, C. Dignard, Laser yellowing: myth or reality? Journal of Cultural Heritage 4 (Suppl. 1) (2003) 238s-244s.

[2] P. Pouli, C. Fotakis, B. Hermosin, C. Saiz-Jimenez, C. Domingo, M. Oujja, M. Castillejo, The laser-induced discoloration of stonework: a comparative study on its origins and remedies, Spectrochimica Acta Part A: Molecular and Biomolecular Spectroscopy 71 (2008) 932-945.

[3] C. Gómez, A. Costela, I. García-Moreno, R. Sastre, Comparative study between IR and UV laser radiation applied to the removal of graffitis on urban buildings, Applied Surface Science 252 (2006) 2782-2793.

[4] P. Maravelaki-Kalaitzaki, V. Zafiropulos, C. Fotakis, Excimer laser cleaning of encrustation on pentelic marble: procedure and evaluation of the effects, Applied Surface Science 148 (1999) 92-104.

[5] S. Klein, T. Stratoudaki, Y. Marakis, V. Zafiropulos, K. Dickmann, Comparative study of different wavelengths from IR to UV applied to clean sandstone, Applied Surface Science 157 (2000) 1-6.

[6] R.M. Esbert, C.M. Grossi, A. Rojo, F.J. Alonso, M. Montoto, J. Ordaz, M.C. Pérez de Andrés, C. Escudero, M. Barrera, E. Sebastián, C. Rodríguez-Navarro, Application limits of Q-switched Nd:YAG laser irradiation for stone cleaning based on colour measurements, Journal of Cultural Heritage 4 (2003) 50s-55s.

[7] C.M. Grossi, F.J. Alonso, R.M. Esbert, A. Rojo, Effect of laser cleaning on granite color. Comparative study of different wavelengths from IR to UV, Color Research \& Application 32 (2007) 152-159.

[8] A. Pan, S. Chiussi, P. González, J. Serra, B. León, Comparative evaluation of UV-vis-IR Nd:YAG laser cleaning of beeswax layers on granite substrates, Applied Surface Science 257 (2011) 5484-5490.

[9] T. Rivas, S. Pozo, M.P. Fiorucci, A.J. López, A. Ramil, Nd:YVO laser removal of graffiti from granite. Influence of paint and rock properties on cleaning efficacy, Applied Surface Science (2012) http://dx.doi.org/10.1016/j.apsusc.2012.09.110

[10] J. Lamas, A.J. López, A. Ramil, B. Prieto, T. Rivas, Monitoring the laser cleaning process of ornamental granites by means of digital image analysis, in: Proceedings of Lasers in the Conservation of Artworks LACONA VIII, 2010, pp. 99-103.

[11] A.J. López, T. Rivas, J. Lamas, A. Ramil, A. Yáñez, Optimisation of laser removal of biological crusts in granites, Applied Physics A 100 (2010) 733-739.

[12] M. Oujja, A. García, C. Romero, J.R. Vázquez de Aldana, P. Moreno, M. Castillejo, UV laser removal of varnish on tempera paints with nanosecond and femtosecond pulses, Chemical Physics 13 (2011) 4625-4631.

[13] P. Pouli, I.A. Paun, G. Bounos, S. Georgiou, C. Fotakis, The potential of UV femtosecond laser ablation for varnish removal in the restoration of painted works of art, Applied Surface Science 254 (2008) 6875-6879.

[14] M. Walczak, M. Oujja, L. Crespo-Arcá, A. García, C. Méndez, P. Moreno, C. Domingo, Castillejo, Evaluation of femtosecond laser pulse irradiation of ancient parchment, Applied Surface Science 255 (2008) 3179-3183.

[15] A.V. Rode, K.G.H. Baldwin, A. Wain, N.R. Madsen, D. Freeman, Ph. Delaporte, B. Luther-Davies, Ultrafast laser ablation for restoration of heritage objects, Applied Surface Science 254 (2008) 3137-3146.

[16] T. Lippert, J.T. Dickinson, Chemical and spectroscopic aspects of polymer ablation: special features and novel directions, Chemical Reviews 103 (2003) 453-485.

[17] P. Pouli, A. Selimis, S. Georgiou, C. Fotakis, Recent studies of laser science in paintings conservation and research, Accounts of Chemical Research 43 (2010) $771-781$.

[18] IGME (Instituto Geológico y Minero de España), Mapa geológico de España Serie Magna, E 1:50.000, 1980, 2nd Ed. Sheet 261 (Tui).

[19] RILEM (Réunion Internationale des Laboratoires d'Essais et de Recherche sur les Matériaux et les Constructions), 1980a, Commission 25 PEM. Protection et Erosion des Monuments. Recommandations provisoires. Essais recommandés 
pour mesurer l'altération des pierres et évaluer l'efficacité des méthodes de traitement. Test No. II.1: Open porosity and Test II.2: Bulk and real densities.

[20] V. Wirth, Flechtenflora: Bestimmung und ökologische Kennzeichnung der Flechten Südwestdeutschlands und angrenzender Gebiete, Verlag Eugen Ulmer, Stuttgart, 1995.

[21] B. Prieto, M.T. Rivas, B.M. Silva, R. Carballal, M.E. López de Silanes, Ecological characteristics of lichens colonizing granite monuments in Galicia (northwest Spain), in: M.A. Vicente, J. Delgado-Rodrigues, J. Acevedo (Eds.), Degradation and Conservation of Granitic Rocks in Monuments, European Commission, Brussels, Great Britain, 1996, pp. 295-300, pp. 263-267.
[22] R. Srinivasan, B. Braren, Ultraviolet laser ablation of organic polymers, Chemical Reviews 89 (1989) 1303-1316.

[23] G. Socrates, Infrared and Raman characteristic group frequencies: tables and charts, third ed., John Wiley and sons, West Sussex, 2001.

[24] A.F. Meisurova, S.D. Khizhnyak, P.M. Pakhomov, IR spectral analysis of the chemical composition of the lichen Hypogymnia physodes to asses atmospheric pollution, Journal of Applied Spectroscopy 76 (2009) 420-426.

[25] J.J. van Thor, N. Fisher, P.R. Rich, Assignments of the Pfr-Pr FTIR difference spectrum of cyanobacterial phytochrome Cph1 using ${ }^{15} \mathrm{~N}$ and ${ }^{13} \mathrm{C}$ isotopically labeled phycocyanobilin chromophore, Journal of Physical Chemistry B 109 (2005) 20597-20604. 